\title{
Evaluating Factors Associated with Radiation-induced Erectile Dysfunction After Stereotactic Radiotherapy
}

\author{
(1) Selvi Tabak Dinçer, (1) Emre Uysal \\ University of Health Science Turkey, Prof. Dr. Cemil Tascioglu City Hospital, Department of Radiation Oncology, Istanbul, Turkey
}

Cite this article as: Tabak Dinçer S, Uysal E. Evaluating Factors Associated with Radiation-induced Erectile Dysfunction After Stereotactic Radiotherapy. J Acad Res Med 2021;11(3):254-61

\begin{abstract}
Objective: Erectile dysfunction (ED) is a common side effect of prostate cancer radiotherapy (RT). Stereotactic body RT (SBRT) is a highly conformal RT technique that utilizes ultra-hypofractionated RT with 4-5 fractions, but the effect of SBRT on sexual function remains uncertain. This study aimed to analyze the possible relationship between SBRT and ED in patients with clinically localized prostate cancer.

Methods: Between January 2013 and December 2019, the factors affecting ED were analyzed in 55 patients with preserved potency following SBRT +/- hormone therapy for low- to intermediate-risk prostate cancer. While planning RT, the penile bulb was delineated as an organ at risk (OAR) in the computed tomography scan. A total dose of 35-36.25 Gy was administered in five fractions of 7-7.25 Gy through alternating-day SBRT treatment with CyberKnife. Erectile function was assessed using the International Index of Erectile Function (IIEF-5) scale at baseline and 3 months, 1 year, and 2 years after SBRT. Groups were formed with respect to post-treatment potency, as measured by IIEF-5.

Results: The median patient age was 68.5 years, and the median follow-up duration was 58 months. After SBRT, $56.4 \%$ of the patients had preserved potency. Age and inclusion of the proximal seminal vesicles in the planning target volume (PTV) were significantly different between the potency groups in the univariate analysis $(p=0.028$ and $p=0.036$ ). In the multivariable analysis, the PTV and inclusion of the proximal third of the seminal vesicles in the PTV were significant in the development of $E D(p=0.038$ and $p=0.020)$.

Conclusion: Although modern RT techniques are used in prostate cancer treatment, erectile function may be affected. Considering the complex mechanisms of ED, it would be erroneous to explain the decline in potency based only on dosimetric factors related to OAR doses.

Keywords: Erectile dysfunction, prostate cancer, radiotherapy, stereotactic body radiotherapy
\end{abstract}




\section{INTRODUCTION}

Prostate cancer ( $\mathrm{PCa}$ ) is the second most frequently diagnosed cancer among men worldwide (1). For clinically localized PCa, treatment options include active surveillance, radical surgery, external beam radiotherapy (EBRT), and brachytherapy with or without androgen-deprivation therapy (ADT) (2). SBRT is a form of high-precision conformal EBRT that allows for ultrahypofractionation (UF) - RT of treatment over 1-5 fractions, and it has comparable efficacy and acceptable toxicities to conventionally fractionated EBRT (3). Based on the low alpha/ beta ratio (1.5-3 Gy) in slowly growing PCa, UF-RT may be radiobiologically favorable in $\mathrm{PCa}$ treatment (4). Different imageguided RT techniques, such as the CyberKnife robotic radiosurgery system (Accuray, Sunnyvale, CA, USA), can be applied in UF-RT to deliver high-dose radiation with large fraction sizes to the target volumes without increasing the dose to adjacent healthy tissues (5). Prospective nonrandomized trials have reported benefits in terms of biochemical disease-free survival with this method that also resulted in similar levels of gastrointestinal and genitourinary toxicities when compared with UF-RT $(6,7)$. Moreover, a large 5 -year randomized trial reported that UF-RT was noninferior to conformal RT in terms of biochemical failure-free survival, overall quality of life, sexual functions, and late toxicity (8).

Nonetheless, erectile dysfunction (ED) is one of the most concerning toxicities following RT. In a meta-analysis, the incidence rates of radiation-induced ED following treatments such as brachytherapy alone, brachytherapy plus EBRT, and EBRT alone were $24 \%, 40 \%$, and $45 \%$, respectively. Comparatively, in surgical treatments, such as nerve-sparing radical prostatectomy, non-nerve-sparing radical prostatectomy, and cryosurgery, ED is observed in $66 \%, 75 \%$, and $87 \%$ of the patients, respectively (9).

In a recently published meta-analysis, the 5-year prevalence of ED was approximately $50 \%$ after RT, but likelihood was dependent on patient age, baseline functions, and comorbidities (10). Furthermore, several studies have reported that ED risk increases with the administration of radiation to the erectile apparatus, particularly the penile bulb (PB) $(11,12)$. However, a review found that no available evidence suggests that avoidance of critical erectile structures during RT was effective in the prevention of these effects (13).

Although veno-occlusive dysfunction of erectile tissues and hemodynamic alterations following RT have been documented, radiation-induced ED is related with more complex mechanisms and remains poorly understood (14). Radiation-induced ED is supposed to be associated with endothelial cell damage on erectile tissues and damage to the arterial supply of the corpora cavernosa regardless of age and comorbidities, in addition to combinations of neurological, vascular, and endocrine disorders (15). However, many studies have shown that decreasing PB dose alone does not directly reduce the incidence of ED, and studies have also suggested performing treatment planning with respect to organs at risk (OARs), such as the neurovascular bundle, internal pudendal artery, and prostatic plexus located posterior of the prostate $(16,17)$.

In recent studies, the optimal $\mathrm{RT}$ modality for localized $\mathrm{PCa}$ treatment remains under investigation; however, modern RT techniques may reduce the incidence of ED by decreasing the RT volume received by critical structures, such as the PB or vasculature, which are normally exposed to high-dose RT $(16,18)$. Thus, this study aimed to evaluate the factors affecting the incidence of ED in patients with $\mathrm{PC}$ a who received SBRT.

\section{METHODS}

\section{Patient Selection}

In this retrospective analysis, we evaluated 68 patients with histopathologically proven low- or intermediate-risk $\mathrm{PCa}$ according to the National Comprehensive Cancer Center (NCCN) guidelines (19), who received SBRT using the CyberKnife at our clinic, from January 2013 to December 2019. Eligible patients were selected according to the following criteria: CT1c-T2c N0 disease, Gleason scores of 6-7, and prostate-specific antigen (PSA) levels of $<20 \mathrm{ng} / \mathrm{mL}$. By contrast, those with previous pelvic RT, those who had undergone prostate surgery, and those with high-risk diseases were excluded.

The validated Turkish version of the 5-item International Index Erectile Function (IIEF-5) scoring system was administered before treatment in all 68 patients. Thirteen patients with severe and moderate ED (IIEF-5 $\leq 11$ ) before RT were excluded from the study, while 55 patients with preserved potency were included to investigate ED following SBRT.

Patients were asked about comorbid diseases such as diabetes mellitus, hypercholesterolemia, or atherosclerosis, which are considered risk factors for ED. Smoking and alcohol consumption were also investigated. Patients receiving ADT were included in the study.

The study protocol was approved by the Ethics Committee of the İstanbul Prof. Dr. Cemil Taşcıoğlu City Hospital (decision no: 369, date: 22.09.2020).

\section{Scoring of Erectile Function and Follow-ups}

The IIEF-5 questionnaire was administered before RT (baseline) and on the $3^{\text {rd }}, 12^{\text {th }}$, and $24^{\text {th }}$ months after treatment. The IIEF5 questionnaire is a diagnostic tool for ED, consisting of five items that are based on the ability to obtain erectile function and intercourse satisfaction. A total IIEF-5 score of 5-25 points can be obtained, and ED is divided into five categories: severe (57), moderate (8-11), mild to moderate (12-16), mild (17-21), and none (22-25) (20). After SBRT, 55 patients were subdivided into two groups according to sexual potency. One group consisted of patients with IIEF-5 > 11 (potent group), while the other consisted of those with IIEF-5 $\leq 11$ (impotent group).

PSA and total testosterone levels were measured at baseline, at 1 month after treatment, and during follow-up visits every 3 months for the first 2 years and every 6 months thereafter. 


\section{Treatment Planning and Delivery}

In patients with organ-confined PCa, 4-5 gold fiducial markers were placed transperineally into the prostate through transrectal ultrasonography. RT was delivered with a CyberKnife radiosurgical device with a 6-megavolt linear accelerator mounted on a robotic arm for real-time tracking. Treatment planning scanning was performed 1 week after fiducial markers were implanted to account for the risk of migration.

All patients underwent simulation with computed tomography (CT) with a comfortably full bladder and empty rectum in the supine position. An appropriate fixation device with knee and foot support was used. Planning CT scans were obtained at $1 \mathrm{~mm}$ thickness and were fused with magnetic resonance images. $\mathrm{CT}$ and magnetic resonance imaging (MRI) datasets were sent for contouring on the CyberKnife planning system. The target definition was based on $\mathrm{CT}$ in conjunction with MRI support for a more precise delineation of the anatomical configuration of the prostate, rectum, bladder, and PB. The Evolution of Radiation Therapy Oncology Group protocols were followed while contouring the OAR, such as the bladder, rectum, bowel, PB, and femoral heads (21). The PB was contoured according to the approach previously described by Wallner et al. (22) and evaluated with dose-volume histogram (DVH) analysis during treatment planning by the same radiation oncologists. Other erectile structures, such as the neurovascular bundle, corpora cavernosa, or internal pudendal arteries, were not specifically contoured.

The clinical target volume (CTV) for patients with low-risk ED included only the prostate, whereas the CTV for those with intermediate-risk ED included the prostate and the proximal third of the seminal vesicles. The PTV was defined as the CTV with an additional margin of $5 \mathrm{~mm}$ in all directions, except for the posterior direction, which was limited to $3 \mathrm{~mm}$ to reduce the risk of rectal toxicity. A total dose of 35-36.25 Gy was prescribed to 95\% of the PTV and was administered in five fractions of 7-7.25 Gy through alternating-day treatment. After contouring, DVH was generated from the CyberKnife plan. The goal of the DVH analysis for the PB was to ensure that the volume receiving 30 Gy dosage was limited to $<3 \mathrm{cc}$. The PTV coverage was assessed using the following parameters: PTV95\% (PTV receiving 35-36.25 Gy) and the maximum and mean dose delivered to the PTV. V30 (volume of the PB receiving $30 \mathrm{~Gy}$ ) and D2\%, D25\%, D50\%, D75\%, and D90\% (mean dose to $90 \%$ of the PB) with the maximum and median doses of each DVH was calculated to obtain the delivered dose to the PB (Table 1).

\section{ADT}

The intermediate-risk group received luteinizing hormonereleasing hormone agonist as an ADT for 6 months so that the treatment was employed 3 months before RT as an neoadjuvant treatment and concurrent ADT in 3 months according to the NCCN recommendation (19). The low-risk group did not receive ADT.

\section{Statistical Analysis}

Categorical variables were presented as number (percentage). Continuous variables were presented with mean \pm standard deviation or median (range) according to the normality of the distribution, which was checked using histograms and analytic methods (Shapiro-Wilk test). The change in IIEF-5 scores over time was analyzed with the Friedman test, and the Wilcoxon test was performed to test the significance of pairwise differences using the Bonferroni correction to adjust for multiple comparisons. Chi-square tests were used to compare the distributions of categorical characteristics between the potent and impotent

\begin{tabular}{|c|c|c|}
\hline \multicolumn{2}{|l|}{ Characteristics } & $n=55$ \\
\hline \multicolumn{2}{|c|}{ Age, mean \pm SD (range) } & $68.56 \pm 7.26(49-85)$ \\
\hline \multicolumn{2}{|l|}{ Smoking } & $31(56.4)$ \\
\hline \multirow{5}{*}{$\begin{array}{l}\text { Comorbid disease, } \\
n=38(69.1 \%)\end{array}$} & $\mathrm{HT}$ & $22(40 \%)$ \\
\hline & CAD & 15 (27.3\%) \\
\hline & DM & $5(9.1 \%)$ \\
\hline & COPD & $5(9.1 \%)$ \\
\hline & $\begin{array}{l}\text { Second primary } \\
\text { cancer }\end{array}$ & $4(7.3 \%)$ \\
\hline \multirow{3}{*}{ T score } & $\mathrm{T} 2 \mathrm{a}$ & 35 (63.6\%) \\
\hline & $\mathrm{T} 2 \mathrm{~b}$ & $14(25.5 \%)$ \\
\hline & $\mathrm{T} 2 \mathrm{c}$ & $6(10.9 \%)$ \\
\hline \multirow{3}{*}{ Gleason score } & $6(3+3)$ & 41 (74.5\%) \\
\hline & $7(3+4)$ & $10(18.2 \%)$ \\
\hline & $7(4+3)$ & 4 (7.3\%) \\
\hline \multirow{2}{*}{$\begin{array}{l}\text { D'amico } \\
\text { classification }\end{array}$} & Low risk & 25 (45.5\%) \\
\hline & Intermediate risk & $30(54.5 \%)$ \\
\hline \multirow{2}{*}{ Total RT dose } & 3500 & $27(49.1 \%)$ \\
\hline & 3625 & 28 (50.9\%) \\
\hline \multirow{2}{*}{ Initial PSA value } & $\leq 10$ & $37(67.3 \%)$ \\
\hline & $>10$ & 18 (32.7\%) \\
\hline \multicolumn{2}{|c|}{ Prostate volume, mean \pm SD } & $55.61 \pm 31.20$ \\
\hline \multicolumn{2}{|c|}{ PSA value, mean \pm SD } & $8.73 \pm 4.33$ \\
\hline \multicolumn{2}{|c|}{ Testosterone value, mean \pm SD } & $3,74 \pm 1.63$ \\
\hline \multicolumn{2}{|l|}{ ADT usage } & $26(47.3 \%)$ \\
\hline \multicolumn{2}{|c|}{ Dosimetric parameters } & Median, (range) \\
\hline \multicolumn{2}{|l|}{ PB volume, cc } & $2.24(0.49-22.58)$ \\
\hline \multicolumn{2}{|l|}{ V30, cc } & $0(0-2.08)$ \\
\hline \multicolumn{2}{|l|}{ D\%25, Gy } & $11.78(2.43-37.33)$ \\
\hline \multicolumn{2}{|l|}{ D\%50, Gy } & $9.16(2.11-34.48)$ \\
\hline \multicolumn{2}{|l|}{ D\%75, Gy } & $6.56(1.75-30.31)$ \\
\hline \multicolumn{2}{|l|}{ D\%90, Gy } & $4.47(160-26.73)$ \\
\hline \multicolumn{2}{|l|}{ D\%2, Gy } & $21.99(2.80-40.21)$ \\
\hline \multicolumn{2}{|l|}{ PBmean, Gy } & $10.11(2.20-33.51)$ \\
\hline \multicolumn{2}{|l|}{ PBmax, Gy } & $23.69(2.91-40.91)$ \\
\hline \multicolumn{3}{|c|}{$\begin{array}{l}\text { SD: standard deviation, HT: hypothyroidism, CAD: coronary artery disease, } \\
\text { DM: diabetes mellitus, COPD: chronic obstructive pulmonary disease, } \\
\text { PB: penile bulb, PSA: prostate-specific antigen, RT: radiotherapy }\end{array}$} \\
\hline
\end{tabular}


separately, the IIEF-5 scores were significantly lower than values before RT and at the $3^{\text {rd }}$ and $12^{\text {th }}$ months in both groups ( $p<0.001$ and $p<0.001$ ), regardless of ADT (Figure 1) (Table 2). No difference was found in IIEF- 5 scores among the measurements at the $3^{\text {rd }}$, $12^{\text {th }}$, and $24^{\text {th }}$ months after treatment.

Significantly larger PTV was observed in the impotent group. The proportion of the patients in whom the seminal vesicle was added to the target volume was higher in the impotent group. No significant differences were observed between the potent and impotent groups with respect to smoking, alcohol consumption, comorbidities (hypertension, diabetes mellitus, coronary artery disease, and chronic obstructive pulmonary disease), T-stage, administration of hormone therapy, and RT dose. No correlation was found between the ED and prostate volume, PB dose (mean or maximum dose), and dose distribution in the PB (Table 3).

In the univariate analysis, age and the inclusion of the proximal seminal vesicles in the PTV significantly associated with ED
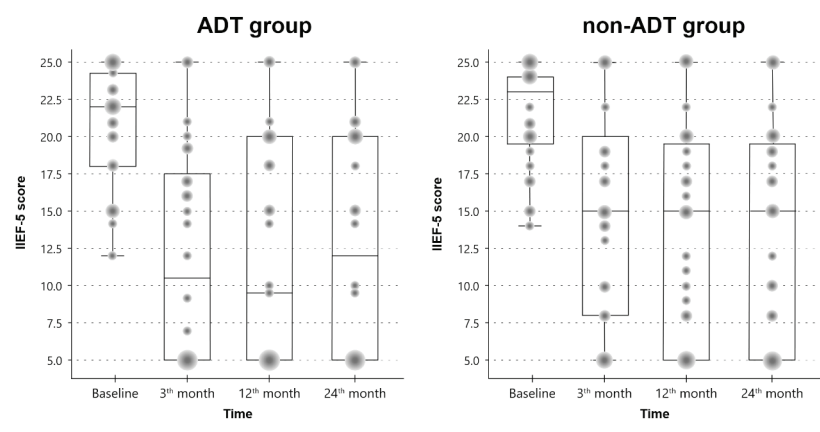

Figure 1. Box plots of the distribution and comparison of IIEF-5 scores with respect to hormone therapy

ADT: androgen-deprivation therapy IIEF-5: 5-item International Index Erectile Function

The patients were followed for a minimum of 24 months after SBRT, and the IIEF-5 scores decreased after RT in all patients $(p<0.001)$. When patients with and without ADT were analyzed

\begin{tabular}{|c|c|c|c|c|}
\hline & IIEF-5 questionnaire & Median (range) & $\begin{array}{l}\text { p value } \\
\text { (Friedman test) }\end{array}$ & $\begin{array}{l}\mathrm{p} \text { value } \\
\text { (Wilcoxon test) }\end{array}$ \\
\hline \multirow{4}{*}{$\begin{array}{l}\text { Total } \\
(n=55)\end{array}$} & Baseline & $22(12-25)$ & \multirow{4}{*}{$<0.001$} & $<0.001^{a}$ \\
\hline & $3^{\text {rd }}$ month & $14(5-25)$ & & $<0.001^{b}$ \\
\hline & $12^{\text {th }}$ month & $12(5-25)$ & & $0.359 c$ \\
\hline & $24^{\text {th }}$ month & $14(5-25)$ & & $0.500^{d}$ \\
\hline \multirow{4}{*}{$\begin{array}{l}\text { with ADT } \\
(n=26)\end{array}$} & Baseline & $22(12-25)$ & \multirow{4}{*}{$<0.001$} & $<0.001^{a}$ \\
\hline & $3^{\text {rd }}$ month & $10.5(5-25)$ & & $<0.001^{b}$ \\
\hline & $12^{\text {th }}$ month & $9.5(5-25)$ & & $0.607^{c}$ \\
\hline & $24^{\text {th }}$ month & $12(5-25)$ & & $0.180^{d}$ \\
\hline \multirow{4}{*}{$\begin{array}{l}\text { non-ADT } \\
(n=29)\end{array}$} & Baseline & $23(14-25)$ & \multirow{4}{*}{$<0.001$} & $<0.001^{a}$ \\
\hline & $3^{\text {rd }}$ month & $15(5-25)$ & & $<0.001^{b}$ \\
\hline & $12^{\text {th }}$ month & $15(5-25)$ & & $0.138^{c}$ \\
\hline & $24^{\text {th }}$ month & $15(5-25)$ & & $0.593^{d}$ \\
\hline
\end{tabular}

a: Baseline vs. $3^{\text {rd }}$ month, b: Baseline vs. $12^{\text {th }}$ month, c: $3^{\text {rd }}$ month vs. $12^{\text {th }}$ month $d: 12^{\text {th }}$ month vs. $24^{\text {th }}$ month, ADT: androgen-deprivation therapy, IIEF-5: 5 -item International Index Erectile Function 


\begin{tabular}{|c|c|c|c|}
\hline & $\begin{array}{l}\text { Potent (IIEF-5 > 11) } \\
n=31\end{array}$ & $\begin{array}{l}\text { Impotent }(\text { IIEF-5 } \leq 11) \\
n=24\end{array}$ & $\mathrm{p}$-value \\
\hline Age ( $>70$ years) & 9 (29\%) & $12(50 \%)$ & 0,112 \\
\hline Adding SV & $14(45.2 \%)$ & 17 (70.8\%) & 0.057 \\
\hline ADT usage & $14(45.2 \%)$ & $12(50 \%)$ & 0.721 \\
\hline Smoking & $19(61.3 \%)$ & $12(50 \%)$ & 0.402 \\
\hline RT dose (3625 cGy) & 17 (54.8\%) & $11(45.8 \%)$ & 0.437 \\
\hline Comorbid disease & $20(64.5 \%)$ & 18 (75\%) & 0.404 \\
\hline HT & $11(35.5 \%)$ & 11 (45.8\%) & 0.437 \\
\hline CAD & $6(19.4 \%)$ & $9(37.5 \%)$ & 0.134 \\
\hline $\mathrm{DM}$ & $3(9.7 \%)$ & 2 (8.3\%) & 0.863 \\
\hline COPD & $3(9.7 \%)$ & $2(8.3 \%)$ & 0.863 \\
\hline \multirow[t]{2}{*}{ Second primary cancer } & $3(9.7 \%)$ & $1(4.2 \%)$ & 0.435 \\
\hline & Mean \pm SD & Mean \pm SD & \\
\hline PSA value & $8.12 \pm 4.06$ & $9.51 \pm 4.64$ & 0.244 \\
\hline Testosterone & $3.79 \pm 1.87$ & $3.68 \pm 1.29$ & 0.798 \\
\hline Prostate volume & $63.11 \pm 31.21$ & $65.05 \pm 42.53$ & 0.714 \\
\hline PTV, cc & $84.76 \pm 38.99$ & $110.10 \pm 59.68$ & $0.023^{*}$ \\
\hline PB volume, cc & $3.08 \pm 3.78$ & $2.31 \pm 1.19$ & 0.298 \\
\hline PBmean, Gy & $13,68 \pm 9.35$ & $11,69 \pm 8.79$ & 0.812 \\
\hline PBmax, Gy & $23.65 \pm 12.80$ & $20.76 \pm 11.57$ & 0.675 \\
\hline D\%2, Gy & $22.23 \pm 12.80$ & $18.98 \pm 11.85$ & 0.624 \\
\hline D\%25, Gy & $17.05 \pm 11.34$ & $14.26 \pm 10.84$ & 0.651 \\
\hline D\%50, Gy & $13.03 \pm 9.66$ & $11.20 \pm 9.17$ & 0.835 \\
\hline D\%75, Gy & $10.04 \pm 8.36$ & $8.82 \pm 7.40$ & 0.598 \\
\hline D\%90, Gy & $8.51 \pm 7.38$ & $7.37 \pm 6.17$ & 0.302 \\
\hline V30, cc & $0.29 \pm 0.56$ & $0.19 \pm 0.46$ & 0.406 \\
\hline
\end{tabular}

following SBRT ( $p=0.028, p=0.036)$. Smoking, ADT usage, comorbid diseases, RT dose, and PB doses were not significant. The multivariable analysis showed that the PTV and inclusion of the proximal seminal vesicles in the PTV were significantly associated with ED likelihood ( $p=0.038, p=0.020$ ) (Table 4).

\section{DISCUSSION}

In this study, we evaluated 55 patients with PCa who, before SBRT, had no worse than moderate ED. These patients had undergone RT with or without ADT and attended follow-up for at least 1 year after RT. The use of ADT and the PB dose were not associated with ED, but logistic regression showed that the higher PTV and the inclusion of the proximal third of the seminal vesicle into the CTV were associated with ED.

Randomized trials comparing patients receiving UF-RT with those receiving conventional fractionation showed similar biochemical control rates and toxicity (gastrointestinal and genitourinary), while enabling the delivery of highly conformal RT $(8,23)$. A study recommends a total dose of 35-36.25 Gy (BED $=70$ Gy vs. 74 Gy, assuming alpha/beta of 3) given in five fractions (7-7.25 Gy), while utilizing image-guided RT techniques in SBRT (24). Besides gastrointestinal and genitourinary toxicity, ED is a known prevalent side effect of PCa treatment; however, research is limited with respect to data concerning sexual outcomes following SBRT (25).

Studies that evaluated the relationships between ED and EBRT have shown decreased potency in patients with PCa $(26,27)$. In the majority of the studies investigating radiation-induced ED, the $\mathrm{PB} / \mathrm{crura}$ is considered an anatomic surrogate in which the application of high-dose RT can lead to ED $(28,29)$, but a recent study found no relationship between ED and RT (30). However, previous studies have recommended limiting the mean dose to $95 \%$ of the PBV $<50$ Gy with conventionally fractionated EBRT 


\section{Table 4. Factors predicting erectile dysfunction}

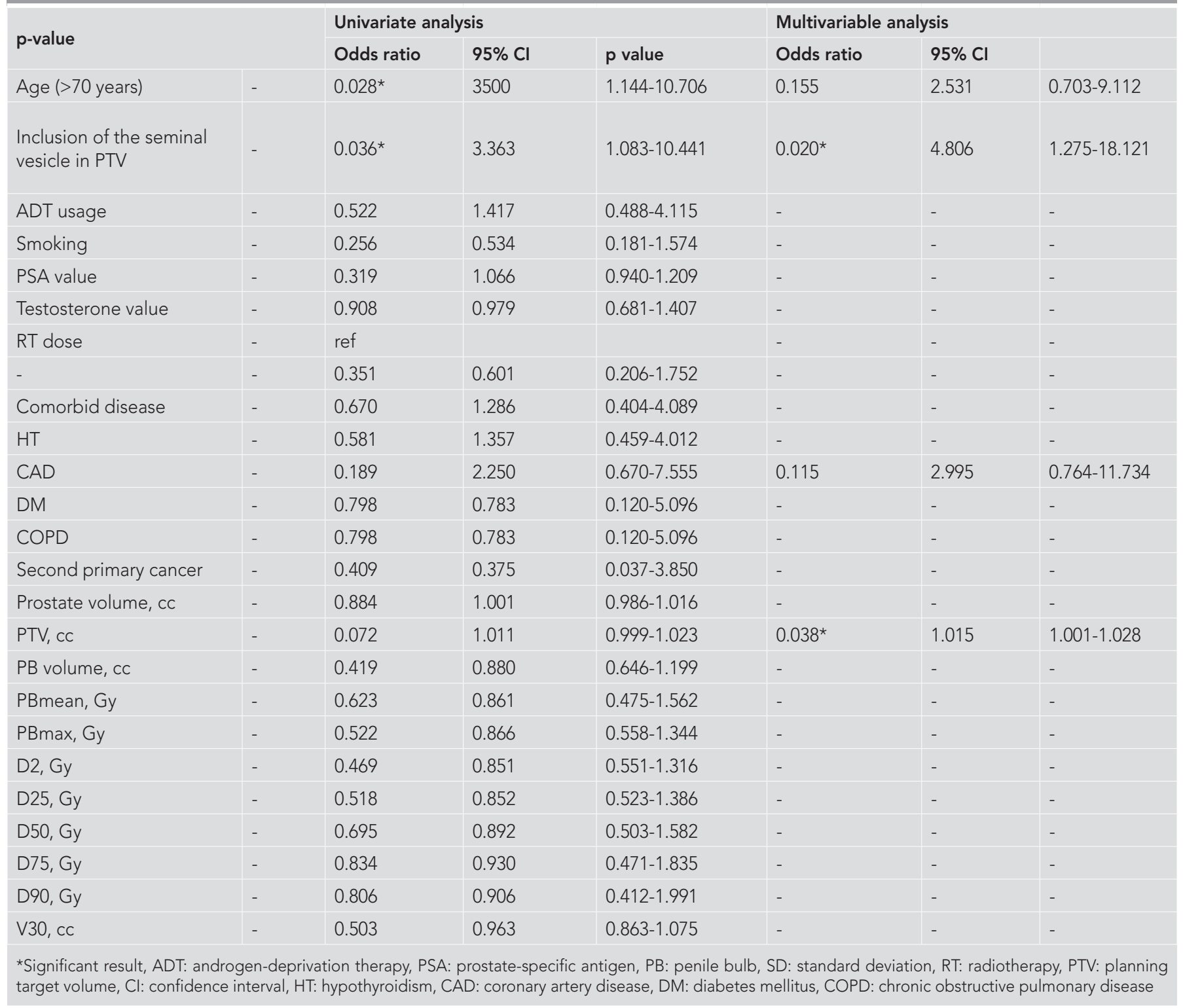

$(31,32)$. In the very recent CHHIP trial, the relationship between $\mathrm{ED}$ and dose to the PB indicated that the PB dose was predictive of ED development after RT - with a threshold mean dose of approximately 20 Gy (33). Recommended PB dose constraints for hypofractionated schedules have not been determined yet (34), and the standard fractionations stated in the Quantitative Analyses of Normal Tissue Effects in the Clinic review need to be validated using data from patients treated with different regimens (13). In the present study, only the PTV was related with ED incidence, regardless of the PB dose. Although the target volume and PTV margin reduction were enabled by SBRT and provided the capability to ensure that the PB volume of receiving 30 Gy did not exceed $3 \mathrm{cc}$, ED was detected in nearly half of the patients. This could be explained by the effects of dose variations delivered to the structures for erectile function; therefore, the effects of RT on ED appear to be associated with other factors in addition to previously shown relationships with the PB dose.
In contrast to gastrointestinal and genitourinary side effects, it is difficult to explain radiation-induced ED only with dosimetric factors linked to OAR doses after SBRT (35). Pretreatment baseline factors should be considered associated with ED. Attributing ED to only RT is difficult because erectile function is closely related with age and other comorbidities, such as cardiovascular disease, hypertension, diabetes, and behavioral risk factors (i.e., obesity, smoking, sedentary lifestyle, and alcohol consumption) (36). Some authors have also suggested that ED can be explained by the effects of post-RT ED (37). In a recent epidemiologic study, older patients were found to have experienced a decline in erectile functions similar to patients without PCa, while ED was observed in up to $44 \%$ of men aged $60-69$ years (38). Consistent with epidemiological data, ED is expectedly seen in approximately half of the patients in this age group, regardless of $R T$; therefore, treatments should be tailored according to age groups and the current status of the patients (39). In the present study, age (>70 
years) was observed as a significant variable associated with ED in the univariate analysis. Comorbidities and lifestyle habits were not identified as prognostic factors for ED following SBRT. Similarly, Dess et al. (37) found that other comorbidities were not significant factors for ED, except for older age.

ED was a common side effect in $60 \%$ of the patients at 2 years post-RT follow-up, and the largest decline in erectile function occurs within the first year after radiation-based treatments and increases with time, predominantly during the first 1-3 years $(40,41)$. In recently published trials, decreased potency was observed in nearly $50 \%$ of the patients following SBRT, with the greatest decline seen during the first year after RT $(37,42)$. This result is similar to our findings that $46.3 \%$ of our patients showed a decline in sexual potency following SBRT in the 3rd and 12th months. The follow-up period was not enough to analyze the factors associated with late sexual side effects and/or to assess the whole group in terms of changes or stabilization of erectile functions; therefore, these may be short-term ED outcomes in patients with PCa treated with SBRT. Despite these results, none of the patients used sexual aids before or after RT, and the most reliable explanations were the high cost of these treatments and no coverage by social health insurance.

Patients who received ADT were not considered ideal in investigating the effect of RT on sexual outcomes, so they were excluded from most of the previous studies. In some studies, no significant difference was found in the erectile function results with the inclusion of the ADT group and no differences were found in the frequency or recovery of sexual potency in the RT alone or RT + ADT groups $(43,44)$. Similarly, ADT had no significant effects on ED in the present study.

This study has several limitations. First, this was a retrospective study from a single center and included a limited number of patients. Therefore, patient characteristics and interpretations may be biased. Second, despite the promising results, data regarding long-term potency preservation after SBRT are lacking. Third, the method of ED measurement by using the IIEF-5 scoring system limited the findings because it is a patient-reported instrument, and this feature may affect the quantification of sexual function. Finally, other erectile structures, such as the neurovascular bundle, corpora cavernosa, or internal pudendal arteries, were not contoured specifically, and only the PB dose was evaluated as a critical component that could contribute to ED.

\section{CONCLUSION}

Although SBRT allows for delivery of highly conformal EBRT, related with risk reduction by avoidance of erectile tissues such as the $\mathrm{PB}$, the risk for radiation-induced $E D$ is similar to other radiation therapy techniques. It appears that explaining the decline in potency based only on dosimetric factors associated with SBRT may be erroneous. Therefore, sexual function is a multifactorial process and should be considered when evaluating ED. Radiation-induced ED will require more studies with highquality data and sufficient follow-up.
Ethics Committee Approval: The study protocol was approved by the Ethics Committee of the İstanbul Prof. Dr. Cemil Taşcıoğlu City Hospital (decision no: 369, date: 22.09.2020).

Informed Consent: Retrospective study.

Peer-review: Internally peer-reviewed

Author Contributions: Surgical and Medical Practices - S.T.D., E.U., Concept - S.T.D., Design - S.T.D., Data Collection or Processing - S.T.D., E.U., Analysis or Interpretation - S.T.D., E.U., Literature Search - S.T.D., E.U., Writing - S.T.D.

Conflict of Interest: No conflict of interest was declared by the authors.

Financial Disclosure: The authors declared that this study received no financial support.

\section{REFERENCES}

1. Torre LA, Siegel RL, Ward EM, Jemal A. Global cancer incidence and mortality rates and trends--an update. Cancer Epidemiol Biomark Prev 2016; 25: 16-27.

2. Keyes M, Crook J, Morton G, Vigneault E, Usmani N, Morris WJ. Treatment options for localized prostate cancer. Can Fam Physician 2013; 59: 1269-74.

3. Loblaw A, Liu S, Cheung P. Stereotactic ablative body radiotherapy in patients with prostate cancer. Transl Androl Urol 2018; 7: 330-40.

4. Miralbell R, Roberts SA, Zubizarreta E, Hendry JH. Dose-fractionation sensitivity of prostate cancer deduced from radiotherapy outcomes of 5,969 patients in seven international institutional datasets: $\alpha / \beta=1.4$ (0.9-2.2) Gy. Int J Radiat Oncol Biol Phys 2012; 82: e17-24. doi: 10.1016/j. ijrobp.2010.10.075.

5. Xie Y, Djajaputra D, King CR, Hossain S, Ma L, Xing L. Intrafractional motion of the prostate during hypofractionated radiotherapy. Int J Radiat Oncol Biol Phys 2008; 72: 236-46

6. Loblaw A, Pickles T, Crook J, Martin AG, Vigneault E, Souhami L, et al; Genitourinary Radiation Oncologists of Canada (GUROC). Stereotactic ablative radiotherapy versus low dose rate brachytherapy or external beam radiotherapy: propensity score matched analyses of Canadian data. Clin Oncol (R Coll Radiol) 2017; 29: 161-70.

7. King CR, Brooks JD, Gill H, Presti JC Jr.Long-term outcomes from a prospective trial of stereotactic body radiotherapy for low-risk prostate cancer. Int J Radiat Oncol Biol Phys 2012; 82: 877-82.

8. Widmark A, Gunnlaugsson A, Beckman L, Thellenberg-Karlsson C, Hoyer $M$, Lagerlund $M$, et al. Ultra-hypofractionated versus conventionally fractionated radiotherapy for prostate cancer: 5-year outcomes of the HYPO-RT-PC randomised, non-inferiority, phase 3 trial. Lancet 2019; 394: 385-95.

9. Robinson JW, Moritz S, Fung T. Meta-analysis of rates of erectile function after treatment of localized prostate carcinoma. Int J Radiat Oncol Biol Phys 2002; 54: 106-8.

10. Gaither TW, Awad MA, Osterberg EC, Murphy GP, Allen IE, Chang A, et al. The natural history of erectile dysfunction after prostatic radiotherapy: a systematic review and meta-analysis. J Sex Med 2017; 14: 1071-8.

11. Mendenhall WM, Henderson RH, Indelicato DJ, Keole SR, Mendenhall NP. Erectile dysfunction after radiotherapy for prostate cancer Am J Clin Oncol 2009; 32: 443-7.

12. Wernicke AG, Valicenti R, Dieva K, Houser C, Pequignot E. Radiation dose delivered to the proximal penis as a predictor of the risk of erectile dysfunction after three-dimensional conformal radiotherapy for localized prostate cancer. Int J Radiat Oncol Biol Phys 2004; 60: 1357-63.

13. Roach M 3rd, Nam J, Gagliardi G, El Naqa I, Deasy JO, Marks LB. Radiation dose-volume effects and the penile bulb. Int J Radiat Oncol Biol Phys 2010; 76(Suppl 3): S130-4.

14. Mulhall J, Ahmed A, Parker M, Mohideen N. The hemodynamics of erectile dysfunction following external beam radiation for prostate cancer. J Sex Med 2005; 2: 432-7.

15. Goldstein I, Feldman MI, Deckers PJ, Babayan RK, Krane RJ. Radiationassociated impotence. A clinical study of its mechanism. JAMA 1984; 251: 903-10.

16. Lee JY, Spratt DE, Liss AL, McLaughlin PW. Vessel-sparing radiation and functional anatomy-based preservation for erectile function after 
prostate radiotherapy. Lancet Oncol 2016; 17: e198-208. doi: 10.1016/ S1470-2045(16)00063-2.

17. Ramirez-Fort MK, Rogerse MJ, Santiago R, Mahase SS, Mendez M, Zheng Y, et al. Prostatic irradiation-induced sexual dysfunction: a review and multidisciplinary guide to management in the radical radiotherapy era (Part I defining the organ at risk for sexual toxicities) Rep Pract Oncol Radiother 2020; 25: 367-75.

18. Buyyounouski MK, Horwitz EM, Price RA, Hanlon AL, Uzzo RG, Pollack A. Intensity-modulated radiotherapy with MRI simulation to reduce doses received by erectile tissue during prostate cancer treatment. Int J Radiat Oncol Biol Phys 2004; 58: 743-9.

19. National Cancer Comprehensive Network (2019) Clinical practice guidelines in oncology, prostate cancer, version 2.2019. Last Accessed Date: 17.04.2019. Available from: https:// www.nccn.org.

20. Rosen RC, Cappelleri JC, Smith MD, Lipsky J, Peña BM. Development and evaluation of an abridged, 5-item version of the International Index of Erectile Function (IIEF-5) as a diagnostic tool for erectile dysfunction. Int J Impot Res 1999; 11: 319-26.

21. Michalski JM, Lawton C, El Naqa I, Ritter M, O'Meara E, Seider MJ, et al. Development of RTOG consensus guidelines for the definition of the clinical target volume for postoperative conformal radiation therapy for prostate cancer. Int J Radiation Oncol Biol Physics 2010; 76: 361-8.

22. Wallner KE, Merrick GS, Benson ML, Butler WM, Maki J, Tollenaar BG. Penile bulb imaging. Int J Radiat Oncol Biol Phys 2002; 53: 928-33.

23. Brand DH, Tree AC, Ostler P, van der Voet $\mathrm{H}$, Loblaw A, Chu W, et al; PACE Trial Investigators. Intensity-modulated fractionated radiotherapy versus stereotactic body radiotherapy for prostate cancer (PACE-B): acute toxicity findings from an international, randomised, open-label, phase 3, non-inferiority trial. Lancet Oncol 2019; 20: 1531-43.

24. Morgan SC, Hoffman K, Loblaw DA, Buyyounouski MK, Patton C, Barocas $D$, et al. Hypofractionated radiation therapy for localized prostate cancer: executive summary of an ASTRO, ASCO, and AUA evidence-based guideline. Pract Radiat Oncol 2018; 8: 354-60.

25. Hunt AA, Choudhury KR, Nukala V, Nolan MW, Ahmad A, Ashcraft KA, et al. Risk of erectile dysfunction after modern radiotherapy for intact prostate cancer. Prostate Cancer Prostatic Dis 2021; 24: 128-34.

26. Pinkawa M, Gagel B, Piroth MD, Fischedick K, Asadpour B, Kehl M, et al. Erectile dysfunction after external beam radiotherapy for prostate cancer. Eur Urol 2009; 55: 227-34.

27. Taira AV, Merrick GS, Galbreath RW, Butler WM, Wallner KE, Kurko $\mathrm{BS}$, et al. Erectile function durability following permanent prostate brachytherapy. Int J Radiat Oncol Biol Phys 2009; 75: 639-48.

28. Rivin del Campo E, Thomas K, Weinberg V, Roach M 3rd. Erectile dysfunction after radiotherapy for prostate cancer: a model assessing the conflicting literature on dose-volume effects. Int J Impot Res 2013; 25: $161-5$.

29. Chasseray M, Dissaux G, Bourbonne V, Boussion N, Goasduff G, Malloreau J, et al. Dose to the penile bulb and individual patient anatomy are predictive of erectile dysfunction in men treated with 125 low dose rate brachytherapy for localized prostate cancer. Acta Oncol 2019; 58: 1029-35.
30. Tøndel H, Lund JÅ, Lydersen S, Wanderås AD, Aksnessæther BY, Jensen $C A$, et al. Dose to penile bulb is not associated with erectile dysfunction 18 months post radiotherapy: A secondary analysis of a randomized trial. Clin Transl Radiat Oncol 2018; 13: 50-6.

31. Roach M 3rd, Winter K, Michalski JM, Cox JD, Purdy JA, Bosch W, et al. Penile bulb dose and impotence after three-dimensional conformal radiotherapy for prostate cancer on RTOG 9406: Findings from a prospective, multi-institutional, phase I/II dose-escalation study. Int J Radiat Oncol Biol Phys 2004; 60: 1351-6.

32. Mangar SA, Sydes MR, Tucker HL, Coffey J, Sohaib SA, Gianolini S. Evaluating the relationship between erectile dysfunction and dose received by the penile bulb: using data from a randomised controlled trial of conformal radiotherapy in prostate cancer. Radiother Oncol 2006; 80: 355-62.

33. Murray J, Gulliford S, Griffin C, Wilkins A, Syndikus I, Staffurth J, et al. Evaluation of erectile potency and radiation dose to the penile bulb using image guided radiotherapy in the $\mathrm{CHHiP}$ trial. Clin Transl Radiat Oncol 2020; 21: 77-84.

34. McDonald AM, Baker CB, Shekar K, Popple RA, Clark GM, Yang ES, et al. Reduced radiation tolerance of penile structures associated with dose-escalated hypofractionated prostate radiotherapy. Urology 2014; 84: 1383-7.

35. Wang K, Mavroidis P, Royce TJ, Falchook AD, Collins SP, Sapareto S, et al. Prostate stereotactic body radiation therapy: an overview of toxicity and dose response. Int J Radiat Oncol Biol Phys 2021; 110: 237-48.

36. Maiorino MI, Bellastella G, Esposito K. Lifestyle modifications and erectile dysfunction: what can be expected? Asian J Androl 2015; 17: 5-10.

37. Dess RT, Hartman HE, Aghdam N, Jackson WC, Soni PD, Abugharib AE, et al. Erectile function after stereotactic body radiotherapy for localized prostate cancer. BJU Int 2018; 121: 61-8.

38. Selvin $E$, Burnett AL, Platz EA. Prevalence and risk factors for erectile dysfunction in the US. Am J Med 2007; 120: 151-7.

39. Capogrosso P. Should we tailor the clinical management of erectile dysfunction according to different ages? J Sex Med 2019; 16: 999-1004.

40. Sanda MG, Dunn RL, Michalski J, Sandler HM, Northouse L, Hembroff $L$, et al. Quality of life and satisfaction with outcome among prostatecancer survivors. N Engl J Med 2008; 358: 1250-61.

41. Mahmood J, Shamah AA, Creed TM, Pavlovic R, Matsui H, Kimura M, et al. Radiation-induced erectile dysfunction: recent advances and future directions. Adv Radiat Oncol 2016; 1: 161-9

42. Obayomi-Davies O, Chen LN, Bhagat A, Wright HC, Uhm S, Kim JS, et al. Potency preservation following stereotactic body radiation therapy for prostate cancer. Radiat Oncol 2013; 8: 256.

43. Gay HA, Michalski JM, Hamstra DA, Wei JT, Dunn RL, Klein EA, et al. Neoadjuvant androgen deprivation therapy leads to immediate impairment of vitality/hormonal and sexual quality of life: results of a multicenter prospective study. Urology 2013; 82: 1363-8.

44. Pilepich MV, Krall JM, al-Sarraf M, John MJ, Doggett RL, Sause WT, et al. Androgen deprivation with radiation therapy compared with radiation therapy alone for locally advanced prostatic carcinoma: a randomized comparative trial of the Radiation Therapy Oncology Group. Urology 1995; 45: 616-23 